\title{
Exploring Student Emotional Engagement in Extreme E-service Learning
}

\author{
https://doi.org/10.3991/ijet.v16i23.27427 \\ Valerie Bukas Marcus $\left({ }^{\bowtie}\right)$, Noor Azean Atan, Shaharuddin Md Salleh, \\ Lokman Mohd Tahir, Sanitah Mohd Yusof \\ Universiti Teknologi Malaysia, Johor, Malaysia \\ valeriebukas92@gmail.com
}

\begin{abstract}
This article reports on qualitative study which explored online student emotional engagement experiences during Extreme e-Service Learning program in a higher education institution. There are very few studies providing indepth perspectives on the engagement experiences of online students, moreover in Extreme e-Service Learning program. This research adopted a case study approach, following 27 online students over one semester. The setting for this study involved undergraduate students who enrol for co-curriculum course that implement Extreme e-Service Learning in one of the public universities in Malaysia. The aim of this study was to explore student's emotional engagement throughout the Extreme e-Service Learning and investigate what makes them engaged emotionally. Data was collected from participant's reflective journal and analysed according to engagement rubric meanwhile open-ended question was analysed using thematic analysis. Researcher found out that participants generally have positive emotions throughout the learning process, and it gradually increased until the end of the course. Main reason of this positive emotional engagement was due to the role of instructors and peers, course design and personal value practiced by participants. One limitation of this study is that it is relatively small but still its finding provide insight to instructor of Service Learning that want to shift to online platform at the same time achieve successful and engaging learning experiences.
\end{abstract}

Keywords — student engagement, emotional engagement, online service learning, e-service learning

\section{$1 \quad$ Introduction}

The closure of education institution due to the spread of COVID-19 and the needs of social distancing shift learning platform into fully online learning. Service Learning is not an exception. During the past one year, many service-learning programs in higher education institutions have been transformed into online format which also known as e-Service Learning [1].

Defined by [1], e-Service Learning (electronic service-learning) is a service learning course where the instruction component, the service component or both are conducted online. E-Service Learning is not totally a new pedagogy. For the past decade, there is 
a growing body of research studying about e-Service Learning in various area [2, 3] and this includes a study examining efficacy of e-Service Learning [4]. Undeniably, eService Learning also produced similar learning outcomes as in traditional Service Learning. Previous research reported that students generate similar generic skills even in online service learning [5].

However, less attention has been paid to the outcomes of Extreme e-Service Learning includes what fosters students' learning and growth throughout the process. Meanwhile, student engagement has become an important predictor of success in improving education quality especially in challenging environment as online learning. Similarly, investigating student engagement in e-Service Learning could promote quality of service and learning outcomes among the students. As the tasks in service learning programs are so challenging, what more if implemented fully online, there is an urgent need to study student engagement in this environment [6] particularly in emotional engagement as it was more difficult for students to feel connected or related to online learning.

[7] indicated that emotional engagement act as mediator between students-instructors interaction, student content and learning persistence in online learning environments. More importantly, emotional engagement trigger motivation which is among the most important predictor of success [8]. Often times, Extreme e-Service Learning which is similar like online distance learning gives learners an isolating experience at times adding into the current situation of social distancing, students cannot avoid of feeling isolated during their learning process. Therefore, understanding the experiences of emotions and the impact on student engagement in Extreme e-Service Learning enables improved course design and institutional support in the future as suggested by [9]. As the area of Extreme e-Service Learning is still understudied, therefore researchers use qualitative approach to explore the emotional engagement of students in Extreme e-Service Learning. Guided by two research questions in mind, "How does student engage emotionally in Extreme e-Service Learning and what foster their engagement in Extreme e-Service Learning?", researchers explored reflective journals and open-ended question to answer these research questions.

\section{$2 \quad$ Literature review}

\subsection{E-service learning}

As stated by [1], e-Service Learning have four different types. First, there is Hybrid Type I where service is conducted on-site, and teaching is conducted online. Class meetings and discussions done virtually whereas students connect with community partner onsite and carry out their e-Service Learning project. When service is conducted online and teaching is conducted on-site, this is categorized as Hybrid Type II. Students is required to attend the class in-person meanwhile the service will be done virtually. For Hybrid Type III, both service and instructions are partially online. Teaching can be both in-person and online depends on the needs, and student can complete their service 
virtually and on-site. Lastly, Extreme e-Service Learning is where both service and teaching are fully online. Class and service both conducted virtually.

\subsection{Stages of E-service learning}

While the learning platform might be different for e-Service Learning, stages of eService Learning is still the same with the traditional Service Learning even though it is conducted in online environment. Generally, Service Learning have five main stages [10]. According to this author, service learning can be seen as the center of curriculum that are dynamically engaging. Kaye (2010) lists five main stages in Service Learning such as (i) inventory and investigation, (ii) preparation and planning, (iii) action, (iv) reflection and (v) demonstration. As the task for some stages are quite similar, for this study researcher combine (i) and (ii) as one phase, (iii) as one phase and (iv) and (v) as one phase which become three main phases mainly to differentiate the students' reflection according to the task by phases. They are known as Preparation and Investigation phase, Implementation phase and Reflection and Demonstration phase.

\subsection{Engagement in service learning}

Majority of research has focused on identifying those factor that are related to students' engagement [11-13] whereas research concerned with students' engagement in e-Service Learning remains limited. The existing research often relates those students engaged well based on their academic performance or their final grade in Service Learning. Some of the research in Service Learning also too focus with learner assessment and program evaluation based on learner attitudes and knowledge acquisition meanwhile assessment approaches overwhelmingly focused on surveys and student reflections [14].

It is crucial to investigate what is happening among students' engagement during eService Learning. This is because student can be engaged but not learning with understanding and students can be learning with understanding but not be able to apply what they are learning to practical matters or in different context [15]. Student engagement also identified as a predictor to academic success in the literature [16]

According to [3], previous researches has been done a lot in regards of design and development of e-Service Learning while there is still no single study investigating students' engagement in e-Service Learning, though e-Service Learning existed from the first place to fulfil this need. Investigation of engagement in e-Service Learning can help to identify which learning activity and what motivates students to engage in this learning environment. Up to date, it is uncertain how student engage in e-Service Learning emotionally, behaviorally, and cognitively. The internal mechanism linking e-Service Learning and student engagement still needs examining.

\subsection{Student engagement}

Studies in students' engagement has been around for a decade. Depending on the context, different definitions in the literature were established to highlight the various 
relevant attributes of engagement. [17] defined student engagement as the time and energy that student devote to educational activities whether it is inside or outside classroom and the policies and practices that education institutions use to involved in these. Meanwhile as stated in [18], they refer student engagement as a meta-construct that includes behavioral, affective and cognitive engagement. Other than that, [19] defined engagement as the level of attention and commitment students have in a lesson.

Student's engagement is divided in to 3 main dimensions: cognitive engagement, behavior engagement and emotional engagement [18]. According to [18], behavioral engagement is the extent to which individuals can be observed to put effort and show persistence to remain involved in an activity or situation. Meanwhile, cognitive engagement is where individuals are cognitively engrossed in a task or activity resulting in a reduced awareness of their surroundings. Emotional engagement is when the individuals experience a positive psychological reaction or attachment towards a specific activity or in a situation.

\subsection{Emotional engagement}

Defined by [18], emotional engagement includes affective reactions in the classroom such as boredom, happiness, anxiety and sense of belonging with school and liking and disliking school. Emotional component of engagement related to students' feeling that reflected by their attitude, belongingness and their opinion towards the school [20].

Emotionally engaged student students are more intrinsically motivated to achieve learning outcomes and participate in class. Students who are emotionally engaged also experience greater psychological well-being in the learning environment thus student's level of engagement is associated with higher academic achievement and mental health [21]. Emotional engagement prompts motivation which is among the most important predictors of success [8]. Positive emotions while learning also promotes students' learning opportunities, resources, students' persistence and effort in their learning. Consequently, this lead to students feels more engaged in learning activities [22]. This calls for a reason of this study, where researchers focused on emotional engagement because emotional engagement in online environment are harder to understood [23]. The emotional process are important in learning, however research on emotion in online learning environment is still scarce [24]. By exploring student emotional engagement in Extreme e-Service Learning setting, this study provides deeper insight into internal mechanism that happened during the learning process and advance the understanding of student engagement in Extreme e-Service Learning.

\section{$3 \quad$ Methodology}

\subsection{Research design}

Researchers decided to design this study based on qualitative research, specifically a case study to answer the research question of "How does student engage emotionally 
in Extreme E-Service Learning and what foster their engagement?". Qualitative research provides deeper insight and thought of respondent. Since this study focused on emotional engagement dimension, it will be easier to measure students' emotion based on their thoughts that was in text form. With correct prompt of questions and helpful technological tool such as ClassDojo that ease their process of sharing, researcher believes that students will be able to express their feelings and thoughts more freely.

\subsection{Participants}

The participants in this study were 27 undergraduate students who participated together to conduct an e-Service Learning program based on multimedia design and animation. The program required students to conduct a series of workshops and facilitate the community, 40 secondary school students aged 13 to 14 years old through Google Classroom and Google Meet in duration of 12 weeks from preparation process until the end.

\subsection{Reflective journal}

The reflective journal mainly included open-ended questions adapted and adopted from [6] like "How do you feel about the activity today? What happened in the activity today? Why? What is your plan for the next time?". Students were asked to complete reflective journal entries after each phase of e-Service Learning. The current study would take advantage of reflective journals to explore student emotional engagement throughout the e-Service Learning activities. The development of coding rubrics for engagement were as follows.

\subsection{Engagement coding rubric}

A coding rubric for student emotional engagement was adapted and adopted from [6]. The engagement rubric already examined in term of validity and reliability by the original author. The rubric included emotional (i.e., positive and negative) engagement. Having taken both the quality and quantity of engagement into account, journals were rated, respectively from 0 (e.g., no description of positive or negative emotion) to 4 (e.g., described strong positive or negative emotions more than two times among the many times mentioned) for Emotional Engagement.

\subsection{Open-ended question}

As researchers were exploring student emotional engagement, it is also important to find out what makes students engaged throughout their Extreme e-Service Learning program. Therefore, researchers prepare an open-ended question towards the end of the program as below:

“Overall, what makes you engaged throughout the e-Service Learning programme?" 


\subsection{Procedure}

The course of ICT for Community, a weekly 2 hour lecturer throughout the semester was designed to integrate Extreme e-Service Learning. The main task of the 27 students was to apply their learning of ICT knowledge gained in the classroom to serve secondary school students. Students from the course were divided into small groups to carry out the implementation of the Extreme E-Service Learning project. After each phase of the project, participants were required to complete their reflective journal in online platform in order to keep their memories and experience in a fresh state of mind. The Extreme e-Service Learning program lasted for 12 weeks. In the end, 27 reflective journal entries were collected for each phase of the e-Service Learning. At the end of the course, students were required to answer the open-ended questions regarding the factor that makes them engaged throughout the program.

\subsection{Data analysis}

Student emotional engagement was assessed via reflective journal. The coded scores at each phase were sum up from student reflective journal to represent the level of engagement of that stage. The validity and reliability of the engagement rubric were examined before this analysis. To identify any difference in interpretations, two research assistants review all the annotated reflective journal thoroughly. The author acted as mediator of any difference in interpretation. For the open-ended questions, thematic analysis was used to identify patterns and themes from the answers given by students.

\section{$4 \quad$ Results}

\subsection{How does students engage emotionally in extreme e-service learning?}

To investigate the dynamic process of emotional engagement, the reflective journal was analysed. The change of emotional engagement throughout Extreme e-Service Learning program was shown in Figure 1.

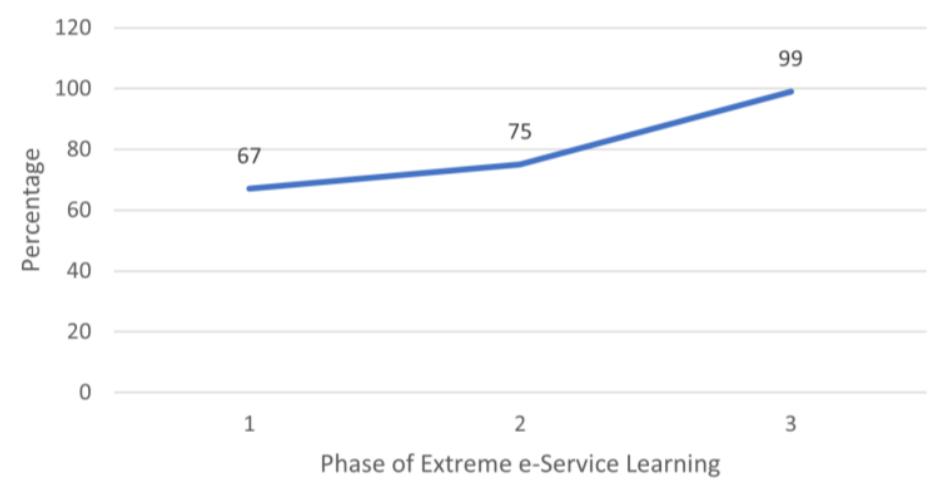

Fig. 1. The Change of Emotional Engagement during Extreme e-Service Learning 
The first stage - Preparation and investigation. As shown in Figure 1, students demonstrated moderate levels of Emotional Engagement. During the first stage, students have mixed feelings about the course. Some students had very high expectations and excited ["I feel very excited because this is the first time that I have a chance to do a module that will be published to teach the community about Pixton Apps based on my knowledge. I also feel enjoyed when doing my job to create a module with content full of images and small tips"'] (excerpted from case S10) meanwhile the others were feeling unclear. A student, S11 shared "In the first few weeks, when we were first told to conduct an e-Service learning, I felt rather unclear about what I was going to do." They also confronted many challenges and problems adapting to the Extreme e-Service Learning program during the first few weeks. One student shared, S14 "From the past few weeks, I felt very challenged in the preparation process of E-SL program. I have not much time to prepare the module Pixton because of there are a lot of homework, tasks and tests that I need to do at the time. I am not really a person that can manage the time very well and it cause me feel a little bit stress at the time."

The second stage - Implementation. As shown in Figure 1, the Emotional Engagement of students showed upward trend. Students started to experience more positive emotions and became more persistent in their service. They also started to feel the sense of belonging and adapt to the environment. ["For me, the implementation of e-Service Learning is crucial. This is because as a university student we should contribute back to the society such as schools' students. For the past weeks we have been teaching using POWTOON and PIXTON web software to secondary school students. This kind of interaction is definitely challenging in this time of Covid-19. However, we organized it online using Google Meet and other platforms. The event was successfully accomplished. I felt the event was very enjoyable and one of the happiest moments in this two years pandemic time."] (excerpted from case S18). As they implement the e-Service Learning, student also feel the sense of accomplishment. One of the students, S23 shared "Ifelt very proud on the implementation of E-Service Learning because we able to teach and share our knowledge to the community. Sharing knowledge is a great act. So personally, for me, it makes me happy because of a good deed. Besides that, the tutorial videos that I have done will be helpful for the community whenever they want to use these apps."

The third stage - Reflection and demonstration. Emotional engagement continues to rose steadily until the end. Most of the students share a lot of very positive emotions towards the end of their service. Some share about their happiness ["Ifeel happy about the overall E-Service learning because as I said before it was a great journey since March till the end. The way we started with a great organization and teamwork made the e-SL achieve its motive. Besides that, I felt proud that I have contributed a little part as Video Tutorial Team and Facilitator of Group 4."'] (excerpt from S23). To our surprised, some students shared that this course is more relaxing compared to the rest on the online learning course they have to take per semester ["I'm happy to take this course, because it such a fun class and more relax compared to the others."] (excerpt from S24). Another student, S12 revealed "I feel happy and enjoyed the E-Service Learning because the whole process is fun and interesting. Besides that, I am grateful and proud to work as a team with other course mates in making this activity successful. 
Initially I thought that this project may feel a bit boring since it is conducted online. However, as we are going through it, I found out that it is very interesting especially about the applications, which are Pixton and Powtoon. I have also created a comic strip and an animation video for the first time as our assignments."

\subsection{What fosters their engagement?}

Answers from open-ended question was analyzed and there are 3 themes that we were able to identify which is course design and online platform used, role of instructors and peers, personal value and functional technological tool. Each theme is discussed in more detail below using pseudonyms to protect students' identity and respect their privacy.

Theme 1: Course design with proper online platform. Findings from the openended question was loaded with students remark about the course design and usefulness of the online platform. Student S1 answered "The way ESL was executed was very fun and creative", meanwhile student S2 claimed that "The way this course designed motivates me a lot." Apart from the overall course design, some student commented about the benefits of doing reflection which is also part of the requirement in e-Service Learning. The student wrote "Doing reflection keeps me on track of what I need to do for eService Learning." As reflection is something that they need to do on weekly basis, researcher decided to use ClassDojo as an online platform for students to submit their reflection due to its user friendly and mobility function that enable students to reflect whenever and wherever they want. One of the students claimed, "Doing reflection in ClassDojo makes me engaged" and there is other student wrote the reason of their engagement is "Doing reflection for every meeting and activity in ClassDojo". Interestingly, one student shared this about ClassDojo "System that thought me to independently on my own task and assignment". Last but not least, there is also a student who wrote "I love ClassDojo and it makes me happy when I used it". All these statements concluded that students were able to engage during their learning process was because of the overall course design that implement effective online platform.

Theme 2: Role of instructors and peers. Analysis from open-ended question also showed the appearance of theme about how instructors and friends help students in this course engage with their learning. A student wrote, "Dedicated lecturer and friends help me to engage in this course." They also wrote down few more that support this theme which detailed as below:

"My group was very hardworking and this makes me engaged throughout the eService Learning"

"The instructor gave a fast response when I need further information in my task"

"The lecturers keep me engaged throughout the e-Service Learning programme"

"Having good lecturers to guide us all"

"Instructor always motivate us to our task and we easily get any information that we need"

"Get to know new friends and helping each other to grow makes me feel like home"

"Fast responses from instructors" 
This finding conclude that instructors and peers play a very important role in fostering student engagement.

Theme 3: Personal value. Researchers also found out that students engaged with their learning because of their personal value which is their sense of responsibility and curiosity. There are two students that answered, "Sense of responsibility" and "The spirit of wanting to know more of something I don't know" as a reason of their engagement. This is an interesting finding as we can see students were actually engaged intrinsically.

In conclusion, the data from reflective journals provided deep and detailed information about student emotional engagement in Extreme e-Service Learning program meanwhile the open-ended question gives clearer explanation on what foster their engagement.

\section{Discussions}

A considerable amount of research has been published related to e-Service Learning in higher education, however they only focused on the design and development or cause-effect relationship in e-Service Learning. There is a need to explore how student engaged in e-Service Learning especially in Extreme e-Service Learning where students were faced with heavy workload that need to be conducted completely in online platform. Especially during pandemic, students were challenged in various ways therefore instructors should pay extra attention to student's emotion. As the tasks in e-Service Learning are so challenging, student engagement in this setting is equally important too. The current study explored student emotional engagement and what makes student engage in their learning in Extreme e-Service Learning. The case study method analysed student's reflective journal and open ended question that answer research questions of this paper as below:

\subsection{How does student engage emotionally in extreme e-service learning?}

In exploring student emotional engagement throughout Extreme e-Service Learning course, researchers found out that their emotional engagement gradually increased until the end of the course. There are moderate positive emotions at the first stage of Extreme e-Service Learning. Students have mixed feeling regarding the course at first due to the newness of the course design to them. There is an uncertainty too that makes students feel anxious and unclear of what is ahead. Furthermore, conducting service learning in pandemic is not an easy task as students faced their own personal challenges in their localities. However, they still manage to anticipate in positive manner regarding the course after instructors explained and gave clear guidelines regarding their project. This finding is similar with [6] where emotional engagement is on moderate level due to students' anxiety during that first experience. Feeling anxious is normal when we were faced by the unknown therefore, instructor plays a crucial role to assist students and clear their doubt along the way. 
Students continued to engage positively in stage 2 which is during the implementation of Extreme e-Service Learning. In this stage, more students share their positive emotions regarding their experience in implementing their project. This revealed that students started to adapt to their new circumstance [25]. As the pandemic happened a year ago, students were required to adapt into online distance learning. Therefore, students in this course are fast to adapt to their new environment. They typically accustomed interacting with each other and with community. They started to feel familiar and already established their teamwork hence the increased of positive emotion they feel in the learning activity. Adaptability indeed promote student engagement under COVID-19 [21].

The most interesting finding was that at the end of the course, students still emotionally engaged with the learning. A possible explanation for this might be as they wrap up their program, students feel sense of accomplishment and achievement in themselves. This also accord with [6] where their participants of the study showed emotional engagement rose steadily as the whole service program is coming to an end so participants tried to make sure they end the service with a comforting feeling.

\subsection{What foster student engagement in extreme e-service learning?}

From the open-ended question, there are three essentials aspects that foster student engagement in Extreme e-Service Learning: (i) course design with proper online platform, (ii) role of instructors and peers and (iii) personal value. There are similarities between the answers expressed by students in this study and those study to improve student engagement described by [15]. Out of five aspects that their research suggests, this study confirm that student engagement can be improve with technology-rich learning environment, relevant learning that involved community and collaboration among teachers and peer-to-peer type of relationship. The finding in this study also similar with few engaging factors reported by [20] that includes teacher-student interaction, quality of learning environment and student characteristics.

Undeniably, instructors play crucial role in facilitating student engagement in Extreme e-Service Learning. In this study, many students mentioned prompt response from their instructor keep them engaged with learning. This is in line with [26] that stated learners will become more engaged when immediate and clear feedback were provided on performance of certain task. When students have a positive relationship with their teacher, it encourages positive attitude among students too and help them to cope with challenges and adversity specifically in online learning. High quality of relationship between students and their teacher influences both academic and non-academic outcomes for students such as engaged in school work, have higher attendance and love to learn more [27].

Interestingly, there are two students that responded with what we defined as personal value as their reason of engagement. Their personal value that consists of sense of responsibility and curiosity related to the finding from [28]. As [28] suggest, to make service learning or learning communities more effective, they should be designed to appeal more to the intrinsic interests of the students as intrinsic motivation is a powerful predictor of when people will work harder, persevere longer, and remain interested in 
an activity for a longer period of time. As a result, creating engaging learning experiences that are intrinsically interesting to students is an important way to increase student engagement. We also emphasized that Extreme e-Service Learning must have instructional design that focused on emotional engagement. This way, it will help to cater to individual learnings need and takes account of student concerns and barriers especially in online learning setting where it was proven disadvantageous in terms of emotional attachment [23].

\section{Conclusion}

The present study explores student emotional engagement in Extreme e-Service Learning and important aspects that foster their engagement. This study has shown that student emotional engagement gradually increased until the end of the course. The second major finding was that there are three crucial elements in fostering student engagement in Extreme e-Service Learning. They are course design with proper online platform, roles of instructors and peers and finally is students' personal value. These findings suggest that in general, student emotional engagement rose steadily throughout the course of Extreme e-Service Learning when the course was designed carefully with proper online platform, continuous guidance and prompt response from instructor together with the peer-to-peer relationship among student that built for the purpose of conducting e-Service Learning project. Another thing to take note from the finding was how students feels that their sense of responsibility and curiosity also foster their engagement in Extreme e-Service Learning. The insight gained from this study may be of assistance for e-Service Learning instructor that want to ensure their students engaged.

\section{$7 \quad$ Limitations and future studies}

This study is relatively small in sample and it cannot be generalized. Future studies should use more sample to reach the saturation of data. Second, additional studies using objective measures or observation are needed to validate the findings. Future studies should triangulate data to expand the findings and better inform future of Extreme eService Learning.

\section{Acknowledgement}

We would like to acknowledge UTM Encouragement Research (UTMER) Grant, Universiti Teknologi Malaysia for sponsoring our work in Cost Center No. Q.J130000.3853.18J82 and Research Management Centre, UTM for managing our grant. 


\section{$9 \quad$ References}

[1] Waldner, L.S., M.C. Widener, and S.Y. McGorry, E-service learning: The evolution of service-learning to engage a growing online student population. Journal of Higher Education Outreach and Engagement, 2012. 16(2): p. 123-150.

[2] Faulconer, E., eService-Learning: A Decade of Research in Undergraduate Online Servicelearning. American Journal of Distance Education, 2021. 35(2): p. 100-117. https://doi.org/ $\underline{10.1080 / 08923647.2020 .1849941}$

[3] Marcus, V.B., et al., A Systematic Review of e-Service Learning in Higher Education. International Journal of Interactive Mobile Technologies, 2020. 14(06): p. 11.

[4] Figuccio, M.J., Examining the Efficacy of E-Service-Learning. Frontiers in Education, 2020. 5(265).

[5] Marcus, V.B., et al., Promoting Students' Generic Skills with the Integration of e-Service Learning Platform. International Journal of Emerging Technologies in Learning, 2019. 14(20): p. 4-17.

[6] Li, Y., et al., The role of subjective task value in service-learning engagement among Chinese college students. Frontiers in psychology, 2016. 7: p. 954.

[7] $\mathrm{Yu}$, J., et al. Exploring the Relationships Among Interaction, Emotional Engagement and Learning Persistence in Online Learning Environments. in 2020 International Symposium on Educational Technology (ISET). 2020. IEEE. https://doi.org/10.1109/iset49818. $\underline{2020.00070}$

[8] Özhan, Ş.Ç. and S.A. Kocadere, The effects of flow, emotional engagement, and motivation on success in a gamified online learning environment. Journal of Educational Computing Research, 2020. 57(8): p. 2006-2031. https://doi.org/10.1177/0735633118823159

[9] Kahu, E., et al., Linking academic emotions and student engagement: Mature-aged distance students' transition to university. Journal of Further and Higher Education, 2015. 39(4): p. 481-497. https://doi.org/10.1080/0309877x.2014.895305

[10] Kaye, C.B., The Complete Guide to Service Learning: Proven. Practical Ways to Engage Students in Civic Ressponsibility, Academic Curriculum, \& Social Action (Minneapolis: Free Spirit Publ.), 2010.

[11] Zhang, X., et al., Learning analytics in collaborative learning supported by Slack: From the perspective of engagement. Computers in Human Behavior, 2017. https://doi.org/10.1016/ j.chb.2017.08.012

[12] Lee, S., et al., Measuring and improving student engagement in clinical training. Educ Prim Care, 2018. 29(1): p. 22-26.

[13] Hussain, M., et al., Student Engagement Predictions in an e-Learning System and Their Impact on Student Course Assessment Scores. Comput Intell Neurosci, 2018. 2018: p. 6347186.

[14] Stetten, N.E., et al., Interprofessional service learning experiences among health professional students: A systematic search and review of learning outcomes. Journal of Interprofessional Education \& Practice, 2019. 15: p. 60-69. https://doi.org/10.1016/j.xjep. $\underline{2019.02 .002}$

[15] Parsons, J. and L. Taylor, Improving student engagement. Current issues in education, 2011. $14(1)$.

[16] Abubakar, A., Y. Abubakar, and J. Itse, Students' engagement in relationship to academic performance. Journal of Education and Social Sciences, 2017. 8(1): p. 5-9.

[17] Kuh, G.D., What We're Learning About Student Engagement From NSSE: Benchmarks for Effective Educational Practices. Change: The Magazine of Higher Learning, 2003. 35(2): p. 24-32. https://doi.org/10.1080/00091380309604090 
[18] Fredricks, J.A., P.C. Blumenfeld, and A.H. Paris, School engagement: Potential of the concept, state of the evidence. Review of educational research, 2004. 74(1): p. 59-109. https://doi.org/10.3102/00346543074001059

[19] Schlechty, P.C., Engaging students: The next level of working on the work. 2011: John Wiley \& Sons.

[20] Subramainan, L. and M.A. Mahmoud, A systematic review on students' engagement in classroom: Indicators, challenges and computational techniques. International Journal of Advanced Computer Science and Applications, 2020. 11(1): p. 105-115. https://doi.org/10. 14569/ijacsa.2020.0110113

[21] Zhang, K., et al., Adaptability Promotes Student Engagement Under COVID-19: The Multiple Mediating Effects of Academic Emotion. Frontiers in Psychology, 2021. 11(3785). https://doi.org/10.3389/fpsyg.2020.633265

[22] Pekrun, R., et al., Positive emotions in education. 2002.

[23] Bond, M., et al., Mapping research in student engagement and educational technology in higher education: a systematic evidence map. International Journal of Educational Technology in Higher Education, 2020. 17(1). https://doi.org/10.1186/s41239-019-0176-8

[24] Tsai, M.-C., et al., Exploring the effects of web-mediated activity-based learning and meaningful learning on improving students' learning effects, learning engagement, and academic motivation. Universal Access in the Information Society, 2019: p. 1-16. https://doi.org/10.1007/s10209-019-00690-x

[25] Rockquemore, K.A. and R. Harwell Schaffer, Toward a theory of engagement: A cognitive mapping of service-learning experiences. Michigan Journal of Community Service Learning, 2000. 7(1).

[26] Stroud, R., The Use of Technology to Support Theories of Learner Engagement. 2019. 137140.

[27] Pedler, M., S. Hudson, and T. Yeigh, The teachers' role in student engagement: A review. Australian Journal of Teacher Education (Online), 2020. 45(3): p. 48-62. https://doi.org/ 10.14221/ajte.2020v45n3.4

[28] Miller, R.L., R.F. Rycek, and K. Fritson, The effects of high impact learning experiences on student engagement. Procedia-Social and Behavioral Sciences, 2011. 15: p. 53-59. https://doi.org/10.1016/j.sbspro.2011.03.050

\section{Authors}

Valerie Bukas Marcus is a PhD student affiliated with Universiti Teknologi Malaysia, Johor Bahru, Johor, Malaysia.

Noor Azean Atan is a lecturer in Faculty of Social Sciences and Humanities in Universiti Teknologi Malaysia, Johor Bahru, Johor, Malaysia.

Shaharuddin Md Salleh is a lecturer in Faculty of Social Sciences and Humanities in Universiti Teknologi Malaysia, Johor Bahru, Johor, Malaysia.

Lokman Mohd Tahir is a lecturer in Faculty of Social Sciences and Humanities in Universiti Teknologi Malaysia, Johor Bahru, Johor, Malaysia.

Sanitah Muhd Yusof is a lecturer in Faculty of Social Sciences and Humanities in Universiti Teknologi Malaysia, Johor Bahru, Johor, Malaysia.

Article submitted 2021-10-02. Resubmitted 2021-10-22. Final acceptance 2021-10-22. Final version published as submitted by the authors. 